\title{
Are Groups the Best Way to Make Decisions? A Literature Review
}

\author{
Juliana Osmani, Ph.D \\ Faculty of Business, Department of Management, University "Aleksander Moisiu", Durres, Albania
}

\section{Doi:10.5901/ajis.2016.v5n1p301}

\begin{abstract}
The decision-making process and the group are two multidisciplinary topics that have captured the interest of many researchers, but at the same time are accompanied by high complexity. The decision-making is considered a continuous and dynamic process that involves a choice, and is oriented to organizational goals. The organizational performance is determined by the decisions taken and their effective implementation. Increasingly, companies have to decide for different situations, never tackled in the past, and often the decisions are not revealed what was expected due to the increased complexity and uncertainty. In this context assumes importance the group decision-making. But the group decisions are really better than individual decisions? Studies on the efficacy of group decision-making lead to different conclusions. However, most of them believe that the group decides better. The main goal of this paper is to show that the comparison between the group and the individual to determine which one is better is a complex process and thus, instead of establishing this is more appropriate defining the criteria to take into analysis before determining whether group should be used or not. So, the first thing done in this paper is discussing about the benefits and limitations that accompany the use of groups with decision-making purpose. Afterwards, with reference to different distinguishing criteria we stop on the type of decisions. The aim is to emphasize that regardless of the many advantages of groups, some contextual factors as risk, uncertainty, complexity, the amount of information available, time limits and the characteristics of the decision as hierarchical level, degree of structuring, repeatability, type of decision-maker and time horizon, should be the main elements to keep in consideration for determining whether it is more appropriate the use of group to make decisions.
\end{abstract}

Keywords: decision-making, group decision-making, individual decision-making, types of decision

\section{Introduction}

Increasingly, managers have to decide for problems or new situations. It has increased the level of risk and uncertainty and the degree of complexity that the decision-maker has to face. Under these conditions, organizations are turning to group decision-making. The question that arises is whether group decisions are really better than individual decisions. Some empirical studies (Sniezek and Henry, 1989; Tindale and Sheffey, 2002; Surowiecki, 2004) showed that on average the result of a group exceeds that of the individual who is part of the same group. One of the reasons why groups can be more effective than individuals in making decisions may be the group's ability to satisfy the need for social belonging. Previously, Maslow (1954) with the hierarchy of needs recognizes the social membership as an important category of motivation. To this we can add the Social Identity Theory of Tajfel and Turner (1979). The theory shows that the commitment of the members increases with the growth of the feeling of belonging to the group. However, we must admit that, as well as Lawrence and Seiler (1965) argued, the relationship between the quality of decisions and the social affiliation is much more complex than one might think. Another feature that favors the effectiveness of the group is that members can put together the different information, so the group is more creative than individual because there are more comparisons and discussions.

\subsection{The aim of the study and research question}

The aim of this paper is to show that the comparison between the group and the individual to determine which one is better to make decisions is a complex process and thus, instead of establishing this is more appropriate defining the criteria to take into analysis before determining whether group should be used or not.

So, in relation to the aim, the research questions are formulated as follows:

1. Are group decisions better than individual decisions?

2. How does the type of decision affect the choice between group and individual decision-making process? 


\subsection{Methodology}

For this paper is adopted the literature based research methodology. So, the study starts bringing a general theoretical framework of the characteristics of group decision-making process, with its benefits and limits. It continues trying to provide a theoretical overview in order to understand how

the decisions diversity may influence the choice between the individual and the group.

This methodology assumes importance because analyzing and discussing the theoretical basis of group decisionmaking, we can:

- $\quad$ find new ideas for future researches;

- define different objects of investigation;

- elaborate appropriate research designs with the respective objectives and hypotheses to be tested.

\section{Advantages and Problems of Groups}

The differences between individual and group decision-making are not a few. Obviously, the group decision-making process is characterized by important benefits, but also by many limits which should not be underestimated. The main benefits of the groups that will be analyzed later, especially refer to the amount of information collected, the level of creativity, the degree of sharing of the decision, the understanding and the quality of decisions, and also to the degree of individual commitment.

Recalling Llaci (2010), the group has a greater volume of information. Certainly, in terms of complexity and uncertainty, the group may not have full information, but as a consequence of the fact that members can belong to different hierarchical levels or different units of the same hierarchical level and the exchange of experience between them, the information collected is greater. Moreover, talking of creativity, the author argues that within a group the creativity is larger than the individual. The discussions and the comparison of opinions help the group to generate more alternatives. In terms of new and non-routine decisions, creativity becomes important. However, as will be discussed later, it cannot be taken for granted the willingness of members to exchange and share their knowledge and information.

Noorderhaven (1995), talking of the benefits of group decision-making, stops on the degree of sharing of the decision. He believes that the acceptability of the alternative chosen by a group is higher. If the decision is made by a single individual can be perceived as an autocratic decision, based on the preferences and interests of the decisionmaker. Under these conditions, it is put into question the legitimacy of the choice. The opposition may be reduced using a group decision-making process. A decision that is not very good, but that is accompanied by a high level of sharing can be much more effective than a really good decision that is not accepted.

A group decision-making process can lead to a better understanding of the choice and so to a more effective decision (Kume, 2002). That is because often within the group there are people who after choosing give the directives of work for its implementation. The probability of failure of a decision is low when the people who have contributed to the decision-making process will also have the responsibility to implement it. As stated at the beginning of this topic, there are empirical evidences showing that the group can make better decisions than the individual. Certainly, as the individual also the group can make bad decisions, but it is generally considered that the group takes high quality decisions (Kume, 2010). That is because a group can generate more possible solutions than just one individual. On the other hand, as a consequence of the exchange of experiences between the members, the group has more tools and interpretative keys to better understand the situation. Regarding this, there might be some objections. So, the group may take the form of a coalition, calling into question the quality of the decisions taken, as the result of a compromise process more than that of the analysis of the available information. The effectiveness of the decision may also be influenced by the level of satisfaction that a decision has to offer to group members. Miller and Monge (1986) concluded that a participatory decision-making process improves motivation. Empirical studies have shown that the group decision-making increases satisfaction (Black and Gregersen, 1997; Wright and Kim, 2004) and self-confidence (Crandall and Parnell, 1994).

Talking about the benefits of the group decision-making process, Surowiecki (2004) introduces the phenomenon of the "wisdom of crowds", considering that the judgment of the group is better than the individual judgments of the members that compose it. For this it is necessary that the group represents a diversity of skills, opinions, information and perspectives. Moreover, each group member must express its point of view without being influenced by other members. However, the author argues that for getting the benefits from the "wisdom of crowds" and moving to the final decision, the group must be able to aggregate the different views of each member.

Lawrence and Seiler (1984) showed that the group leads to a higher level of productivity and increases the motivation and job satisfaction of the members. This may stem from the fact that the group represents a useful tool for the 
growth and the development of the individual members (Cooke and Slack, 1984). In conditions of uncertainty and complexity, the group offers psychological support, helpful to face with any of the external pressures. Moreover, the groups are able to organize better the decision-making process, dividing a complex task into simpler parts to be assigned to individual members.

It needs also to discuss about some aspects considered problematic for group decision-making. Hereinafter are analyzed some of the main limitations of group decision-making process, as the influence of the conductor or leader of the group on the decision process, the groupthink and polarization, the time required for deciding and the use of common information excluding the unique knowledge.

In the group decision-making can happen that the final decision is taken by an individual. It is the case of one of the important limitations of the group. On the pattern of Vroom and Yetton (1973) about the group leadership styles that can be adopted, it can be easily detected the dominance of the individual. Four of the five leadership styles described by them show that the final decision is the responsibility of the conductor or leader of the group.

The greatest disadvantages of group decision-making are considered groupthink and polarization. The first who spoke of groupthink was the social psychologist Janis (1982). He defined this concept as the tendency of groups to converge rapidly towards a decision. Instead of using debates, compare different opinions and reach convergence in the stage of choosing, the groupthink makes decision process to much convergent at the first stage. However, the groupthink does not occur in all groups. For the author, if the level of cohesion of the group is high and the group is very closed the convergence is easy. Even the time plays an important role. More the group has to decide quickly, more undergoes the groupthink. The phenomenon also arises when members have the same ideas and opinions and act in a hostile manner towards those who think differently. Among the other conditions which favor the groupthink, Janis (1982) lists the style of leadership. When the leader of the group adopts an authoritarian style and is committed to orient towards compliance the members that try to divert, increases the risk of groupthink.

It must be emphasized that the author did not stop only to the description of the phenomenon and the conditions that favor it, but has also tried to identify how to prevent it. For Janis (1982) the key is to reduce the cohesion of the group. In this regard, he suggests a decision-making process similar to the normative model. Besides the reduction of cohesion, also the leader's behavior can help to prevent the groupthink. For this he must be open, informal and must support the divergent opinions, encouraging group members to express their criticisms and objections, as well as he should facilitate the gathering of external information. Even when the consensus was reached, the group members should be encouraged to rethink and find possible imperfections (Kinicki and Kreitner, 2009). In this regard, a group member may assume the role of devil's advocate.

The polarization is when the decision of a group is more extreme than the average of individual opinions (Stoner, 1961). It occurs more for new problems or situations or when the group is in the early stages of its life cycle and may have several causes. Thus, the polarization can result from social comparison caused by competition between the members to support the view more socially desirable (Noorderhaven, 1995). To present himself in a more positive light, the individual tends to accept the decision which represents the point of view of the majority. Another explanation can be found in the search for relevant topics. In this case, the polarization depends on the amount of the arguments in favor and disfavor of the problem (Burnstein and Vinokur, 1977). In other situations, the polarization can occur due to the increased identification with the ingroup ${ }^{1}$.

Another major problem that accompanies the group decisions-making is the time required to get to the final decision (Nooderhaven, 1995; Vroom and Yetton, 1973). One reason for this could be the conflict between the members of the group or the high diversity of ideas and opinions that make difficult the consensus. The time limitations may lead the group to choose the first alternative identified. In fact, often happens that is accepted the first solution (Kume, 2010). As a result, even if the other alternatives are better, they hardly are taken into analysis. The choice of the first alternative proposed occurs when the group is composed of members that in addition to the decision-making process are also involved in other activities and important tasks, so the greater volume of work does not allow the analyze of all the possible solutions.

As indicated above, one of the most important benefits of the group is the capacity to collect a larger amount of information, because the group members have different knowledge, which if made available to the others helps to better understand the problem or situation and consequently the identification of more alternatives. But in fact, often happens that the unique information is not taken into account and the tendency is to rely only on the common information. It is in

1 This type of polarization can be better understood in the context of Social Identity Theory of Tajfel e Turner (1979). 
this case the effect of common knowledge, considered one of the most important problems of the group since it threatens its creativity. Numerous studies have shown that even when the unique information is cited during the discussion, the final decision is influenced primarily by common information (Stasser and Titus, 1985; Gigone and Hastie, 1993). The effect of common knowledge occurs when the situation for which the group has to decide is not new. Moreover, if the number of group members who possess the unique information is reduced and if this information is not reliable, the effect of common knowledge increases.

Stasser e Titus (1985) studied the effect of common information in laboratory conditions with the objective of studying the "paradigm of the hidden profile". This paradigm means the manipulation of information in order to know what information has each member.

So, to study the effect of common knowledge Stasser and Titus (1985) used a simple case where a group of three people had to choose between two alternatives: $A$ and $B$. The information about the alternatives were such that for seven reasons the favorite alternative was $A$ and for four reasons was $B$ the preferred alternative. In the first case, the information on the two alternatives $A$ and $B$ were distributed equally among the group members. Thus, in the condition with shared information all preferred $A$ instead of $B$. In the second case, a part of the information regarding $A$ and $B$ was not shared. But even if the arguments in favor of $A$ and $B$ are reduced, for example in three reasons for which prefer $A$ and two for $B$, the alternative $A$ is the one that continues to be chosen. In the third condition, three of the reasons that favor the choice of alternative A are not shared, but are all those that support the alternative $B$. In this case, the preference for the alternative A decreases, but is strengthened after the group discussion. Both, in the second and third condition the group is influenced by the effect of polarization (Stasser and Titus, 1985). The fourth condition is more extreme of the third, only one reason that supports A is shared, while other reasons are not shared. In this case is preferred alternative $B$ favored by four reasons, distributed equally among the members.

But how can be explained the effect of common knowledge? In this regard, several explanations have been proposed. So, Stasser (1992) reports the probabilistic sampling of the information. More people have the same information, greater is the possibility that this information can be exchanged between members of the group. Other authors refer to the confirmation effect. Often, members of the group evaluate the information they have and identify the preferred alternative before starting the discussion. Consequently, they will be influenced more by the information that confirms their initial idea (Staw, 1997). If some members base their ideas on the shared information, the unique ones will not be taken into consideration (Gigone and Hastie, 1993). It can happen that the members of the group put in doubt their abilities, especially if it is a new and very important decision. In these cases, their commitment to the decision-making process will increase only if they exchange the shared information (Wittenbaum, Hubbell and Zuckerman, 1999). A further condition that favors the effect of common knowledge is the group communication process. Usually, people communicate messages that converge with the knowledge of the recipients. This is not permitted by unique knowledge (Wittenbaum and Bowman, 2004).

The question that arises is what to do to reduce the effect of common information. Stasser and Stewart (1992) recommended verifying the source of unique information and give more time to the group to decide. In this way, the group members are stimulated to generate and take into analysis more alternatives.

Sometimes happens that the group decision-making is perceived by some managers as a threat for the personal prestige and power, while others are averse to group decisions because they lack confidence in other people. But not always a participatory decision-making process is the best way to make decisions. There are situations for which is preferred an individual decision-making process (Kume, 2002). So, the time factor is very important. Often there is no time to compose the group and wait for it to reach the consensus. Moreover, when a decision requires unique knowledge, a group decision-making may be inefficient and costly for the company. On the other hand, it often happens that for arriving at the final choice is needed to make available for all members information that are confidential. In this case, it would be appropriate a decision-making process centered on the individual. In addition, if only one individual will have the final responsibility for the decision, it makes no sense using a group to make the decision (Kume, 2010). The individual as a member of the group is more risk seeking. He feels safer in the event of a wrong decision, because there is no individual responsibility, and no one can point the finger against him (Wallach, Kogan, and Bem 1964). The increased risk-taking as member of a group may stem from the fact that who assumes the role of the leader is risk-seeking and thus exerts its influence on the others. Moreover, Kume (2010) argues that more the individual is risk-taker, more is favored for promotions.

In conclusion, we can say that the group decision-making processes are useful in the case of non-periodic and non-routine decisions, characterized by uncertainty. On the contrary it would be preferable an individual decision-making process. 


\section{Types of Decisions}

Corporate decisions are different. In the previous topic it was discussed about the fact that not all the decisions have to be made through group processes. In this regard, it was considered necessary to report the classification and distinction of company decisions with reference to different criteria.

Recalling Drucker (1954), corporate decisions are distinguished in strategic decisions and tactical decisions. Strategic decisions refer to the future of the company, are important and non-routine. In addition, are long-term decisions and characterized by high level of complexity and uncertainty (Thompson and Strickland, 2001). These decisions are made by the top management. Often are considered unique because are taken only once, but anyway are rare decisions with consequences on all hierarchical levels. Kume (2003) believes that strategic decisions affect the company's key activities, defining the relationship between the latter and environment. Instead, tactical decisions, which are nothing but strategic decisions further detailed, are medium-term. Consequently they have an instrumental role in relation to strategic decisions. Can also be defined functional decisions because are made by tactical managers. The risk that accompanies this type of decisions is low compared to strategic decisions. Strategic decisions, as well as tactics require group decision-making processes, to minimize the risk and uncertainty.

Even the type of manager can help to classify decisions. So, recalling the concept of "managerial pyramid" of Anthony (1965), to the categories of decisions listed above may be added a third, operational decisions. These decisions are considered simple, routine and short-term. Are taken by the operational managers, also called supervisors or first line managers, but since these decisions are accompanied by low risk may be delegated to the base of pyramid (Jones and George, 2008). If tactical decisions are instruments to achieve the strategic decisions, operational decisions are tools for making tactical decisions.

The decisions can be distinguished also according to their frequency. Simon (1960) distinguishes between programmed and non-programmed decisions. Programmed decisions are routine and recurrent and are taken by a specific predetermined procedure (Jones and George, 2008). These decisions are structured and so clearly defined that the decision-maker knows very well the problem/ situation and the alternatives to be considered. Since the decision is not new but repetitive, the decision-maker knows the procedure to be followed (Bateman and Snell, 2013). These decisions are made by tactical and operational managers. Moreover, are short or medium term decisions, so do not require deep analysis and are often delegated to lower hierarchical levels, because in case of errors the cost of the adjustment is low (Bateman and Snell, 2013). For programmed decisions we may also discuss if they are really decisions. The doubt arises because these decisions often are made without realizing that it is making a decision, because are repetitive decisions and therefore considered a normal part of managerial work. Furthermore, the decision-making process may not take place as reported by Simon (1960) and the procedure described may be such that eliminates some stages of the rationally-normative process.

On the other hand, non-programmed decisions are unplanned and unstructured, new decisions for which there is no fixed and predetermined procedure. The problem is not clearly defined and is hard to distinguish the possible solutions (Bateman and Snell, 2013). Thus, managers must conclude in conditions of an incomplete understanding of the situation and the possibility of making wrong decisions and the level of uncertainty increases. These decisions generally are competence of top managers and tactical managers and must not be delegated. Since decisions are new, they are often based on intuition and it runs the risk that may be subjective decisions (Jones and George, 2008). The non-programmed decisions must be taken in group, instead the programmed decisions, being routine decisions which do not require different information and knowledge, should be focused on the individual level.

Considering the various theories of decision-making, we can also refer to the type of decision-maker for distinguishing between different decisions. According to the classic model, the rational decision-maker doesn't take into account the uncertainty and ambiguity, because the environment doesn't influence the decision-making process. The analysis of the problem/situation is based on complete and objective information and the decision-maker based on economic reasons, so the final choice is optimal. In this case, we talk of bureaucratic or deterministic decision, because is taken according pre-established rules and procedures that can be applied to all situations (Varvelli and Varvelli, 2001). The rules and procedures are result from the fact that the problem is repetitive. The advantage of the bureaucratic decision is being rapid, because does not require special analysis and for these characteristics is taken individually.

Recalling Simon (1957) and the concept of bounded rationality, the decision-making often based on intuition. According to Driver, Brousseau and Hunsaker (1990) this type of decision is called intuitive or emotional decision. Due to its characteristics is the opposite of bureaucratic decision. There isn't time series, the problem is new, it never tackled in the past and the risk is very high. Also, we cannot establish rules or standard procedures. In order to minimize the limits of rationality and reduce the subjective nature, a group decision-making process would be appropriate. Moreover, the 
authors argue that the limited rationality can also lead to probabilistic or statistical decision. The information collected is not complete and moreover the decision taken offers no warranty regarding the elimination of the problem (Varvelli and Varvelli, 2001). However, the risk is less compared to the risk that accompanies the intuitive decision and maybe for reducing it, would be better a participatory decision-making process.

At the end, we have the creative decision that is based on the use of creative methods and gives importance to intuition. The decision is called random or creative (Driver, Brousseau and Hunsaker, 1990). Is not a repetitive decision and therefore also in this case the risk remains high. But as the group stimulates further the creativity, this kind of decision-maker would feel better as member of a group, preferring so a group decision-making process instead of an individual process.

With reference to the time horizon, we can distinguish long-term decisions with a time horizon greater than 5 years, medium-term decisions with a time horizon from 1 to 5 years and short-term decisions with a time horizon less than 1 year (Jones and George, 2008). With the increase of the time horizon, increases also the risk and the degree of uncertainty, encouraging group decision- making processes.

Taking up the types of decisions according to Simon (1960) previously reported, Gorry and Scott Morton (1971) propose another distinction between structured, unstructured and semi-structured decisions. With structured decisions authors refer to programmed decisions and with unstructured decisions to those non-programmed. The semi-structured decisions have characteristics in common with programmed and non-programmed decisions. So for these decisions, the decision-maker can refer to the data and information available, but also becomes necessary the personal judgment and experience (Llaci, 2010). The degree of structuring defines the opportunity to formalize the decision-making process. Strategic decisions are unstructured, not formalized and cannot be based on pre-established models. Even tactical decisions cannot be structured, but in this case the degree of non-structuring is minor compared to strategic decisions. Operational decisions are decisions that can be structured, predictable and routine. For these decisions, there are established procedures and the formalization is high. More the degree of formalization is high, much more decisions require individual processes since the risk and complexity decrease due to standard procedures.

The context within a decision is made can vary significantly. Environmental conditions and the collection of information determine the effectiveness of the decision-making process. There are three conditions under which a decision can be taken (Schermerhorn, Hunt and Osborn, 1997). The first includes decisions under certainty, for which the decision-maker is familiar with both options and the outcome of the decision can be predicted accurately. In such conditions, the decision-maker has complete information and is able to list all the possible solutions. Under certainty the probability that an alternative leads to the envisaged consequences is equal to 1 . The decision-making under certainty is a phenomenon that never happens, because the external conditions rarely can be predicted perfectly (Kume, 2010). The second condition refers to decisions accompanied by risk. Under risk only part of the information is available and the decision-maker cannot identify all the possible alternatives and the probability that the chosen alternative leads to the envisaged consequences is a value between] 0; 1 [. In this case, to improve the decision-making and reduce the risk are used mathematical and statistical techniques such as risk analysis, decision tree etc (Llaci, 2010). The decision-making under risk occurs often in practice. On the other hand, we have decisions made under uncertainty. It is the condition in which we do not have sufficient information to forecasting the outcome of the decision. Even the little information that the decision-maker can have is not totally reliable and he cannot estimate the interactions between the different variables (Kume, 2010). Today, uncertainty is a typical condition for the decision-maker and he has important difficulties on identifying the possible alternatives and is not able to calculate the probabilities. These decisions as well as risk decisions require group decision-making processes, to minimize the risk and uncertainty.

The following table is a summary of what was discussed above, with the aim of helping to better understand why the decisions that require group processes are those strategic and tactical.

Tabel 1: Types of decisions

\begin{tabular}{|c|c|c|}
\hline STRATEGIC DECISIONS & TACTICAL DECISIONS & OPERATIONAL DECISIONS \\
\hline $\begin{array}{l}\text { - very important decisions for the corporate } \\
\text { - unique or very rare } \\
\text { - taken by top-managers } \\
\text { - cannot be structured } \\
\text { - long-term } \\
\text { - uncertainty conditions }\end{array}$ & $\begin{array}{l}\text { - important to achieve the strategic decisions } \\
\text { - periodic decisions } \\
\text { - taken by tactical managers } \\
\text { - cannot be too much structured } \\
\text { - middle-term } \\
\text { - risk conditions }\end{array}$ & $\begin{array}{l}\text { - important for the tactical decisions } \\
\text { - daily frequency } \\
\text { - taken by first line managers } \\
\text { - can be structured } \\
\text { - short-term } \\
\text { - certainty conditions }\end{array}$ \\
\hline
\end{tabular}

Source: author elaboration 


\section{Conclusions}

In the management literature, the decision-making occupies an important place. Talking about decisions-making one of the arguments or topics of more interest, which have captured the attention of researchers of the field, is the use of groups to reach the final solution. Most of articles and studies on our knowledge that discuss about groups decisionmaking are focused on comparing groups with the decision-making process at the individual level.

Many are the benefits of using the group to take decisions. Above, we discussed on some of them considered as the most important advantages of the groups as the amount of the information collected, the creativity, the degree of acceptability of the decision, the understanding and the quality of choice and the level of personal commitment and motivation. But it is not fair if we don't reflect about the other side of the coin. The use of groups for taking decisions is associated with some limits. So, above were analyzed several of them as the influence of the conductor or leader of the group in the decision-making process, the groupthink and polarization, the time required for achieving the consensus or the final decision, the use of common information excluding the unique information.

It must be emphasized that for determining whether groups are better than individuals in making decisions is very difficult and we believe that it would be appropriate defining the criteria that must be analyzed to determine whether for a situation or problem would be better group or individual processes. A very important element that should not be forgotten is the type of decision and its features. In this regard it was discussed above. Thus, the strategic decisions are very important for the organization and relate to its future, are long-term decisions and accompanied by a high level of risk and uncertainty. Often, the decision-maker has to conclude in conditions of limited information and so the intuition plays an important role. But intuition sometimes leads to bad decisions. Then, since strategic decisions are important decisions because affect all hierarchical levels is necessary being qualitative decisions. For these decisions are appropriate group decision-making processes, as a way for reducing the limited rationality, uncertainty and the possibility of bad decisions. Even for department decisions the use of groups would bring many benefits. Tactical decisions are important because tactical level connects the strategic level with the operational level. Tactical decisions are medium-term, accompanied by risk and in most of the cases are non-structured. Everything changes talking about operational decisions. Since these decisions are routine, structured and short-term, may be taken by a single individual. In fact, often the operational managers to reduce the volume of their work delegate some of the decisions to lower hierarchical levels, because the risk is low and being repetitive decisions the possibility of errors is low. Even in the case of errors, being not very important decisions for the organization, the cost of adjustment remains low. For all the above characteristics, we believe that, if for these decisions are used group processes, organizations will have more costs than benefits.

It should be noted that, besides the characteristics of the situation, also other factors must be considered for determining whether to use or not group decision-making processes as time available, the characteristics of employees and their attitude towards group decision-making etc. These may be subject for future research and articles related to group decision-making.

\section{References}

Anthony R.N. (1965), Planning and control systems. In Llaci Sh. (2006), Manaxhimi, Tiranë: SHBLU

Bateman T.S., Snell S.A. (2013), Management: Leading and collaborating in a competitive world, New York: McGraw-Hill

Black J.S., Gregersen H.B. (1997), Participative decision-making: An integration of multiple dimensions, Human Relations, Vol. 50, No. 7, p. $859-879$

Burnstein E., Vinokur A. (1977), Persuasive argumentation and social comparison as determinants of attitude polarization, Journal of Experimental Social Psychology, Vol. 13, p. 315-332

Cooke S., Slack N. (1984), Making management decisions, London: Prentice-Hall International

Crandall W., Parnell J. (1994), On the relationship between propensity for participative management and intentions to leave: reopening the case for participation, Mid-Atlantic Journal of Business, Vol. 30, No. 2, p. 197-209

Driver M.J., Brousseau K.E., Hunsaker P.L. (1990), The dynamic decision maker, New York: Harper \& Row

Drucker P. (1954), The practice of management, New York: Harper \& Row

Gigone D., Hastie R. (1993), The common knowledge effect: Information sharing and group judgment, Journal of Personality and Social Psychology, Vol. 65, No. 5, p. 959-974

Gorry G.A., Scott Morton M.S. (1971), A framework for management information systems, Sloan Management Review, Vol. 13, No. 1, p. 21-36

Janis I.L. (1982), Groupthink: Psychological studies of policy decisions and fiascoes, $2^{\text {nd }}$ ed., Boston: Houghton Mifflin

Jones G.R., George J.M. (2008), Contemporary management, Boston: McGraw-Hill//rwin, $5^{\text {th }}$ Edition

Kinicki A., Kreitner R. (2009), Organizational behavior, 4th edition, McGraw-Hill//rwin 
Kume V. (2002), Managerial decision-making, 3rd Edition, Tirana: SHBLU

Kume V. (2003), Strategic Management, Tirana: Pegi

Kume V. (2010), Managerial decision-making, 4th Edition, Tirana: Pegi

Lawrence P.R., Seiler J.A. (1965), Organizational behavior and administration, New York: Irwin-Dorsey

Llaci Sh. (2010), Management, Tirana: AlbPaper

Maslow A. (1954), Motivation and Personality, New York: Harper \& Row

Miller K.I., Monge P.R. (1986), Participation, satisfaction and productivity: A meta-analytical review, Academy of Management Journal, Vol. 29, No. 4, p. 727-753

Noorderhaven N.G. (1995), Strategic decision making, Wokingham: Addison-Wesley Longman

Schermerhorn J.R., Hunt Jr.J.G., Osborn R.N. (1997), Organizational behavior, New York: John Wiley \& Sons

Simon H.A (1957), Models of man, New York: John Wiley and Sons

Simon H.A. (1960), The new science of management decision, New York: Harper \& Row

Sniezek J.A., Henry R.A. (1989), Accuracy and confidence in group judgment, Organizational Behavior and Human Decision Processes, Vol. 43, No. 1, p. 1-28

Stasser G. (1992), Pooling of unshared information during group discussion. In Wittenbaum G.M., Hollingshead A.B., Botero I.C. (2004), From cooperative to motivated information sharing in groups: moving beyond the hidden profile paradigm, Communication Monographs, Vol. 71, No. 3, p. 286-310

Stasser G., Stewart D. (1992), Discovery of hidden profiles by decision-making groups: Solving a problem versus making a judgment, Journal of Personality and Social Psychology, Vol. 63, No. 3, p. 426-434

Stasser G., Titus W. (1985), Pooling of unshared information in group decision making: Biased information sampling during discussion, Journal of Personality and Social Psychology, Vol. 48, No. 6, p. 1467-1478

Staw B.M. (1997), The escalation of commitment: an update and appraisal. In Shapira Z. (2002), Organization decision making, New York: Cambridge University Press

Stoner J.A.F. (1961), A comparison of individual and group decisions involving risk. Unpublished master's thesis, Massachusetts Institute of Technology, School of Industrial Management

Surowiecki J. (2004), The wisdom of crowds, New York: Anchor Books

Tajfel H., Turner J. (1979), An integrative theory of intergroup conflict. In Williams J.A., Worchel S. (Eds.), The social psychology of intergroup relations, p. 33-47, Belmont, CA: Wadsworth

Thompson A.A., Strickland A.J. (2001), Strategic management: Concepts and cases, New York: McGraw-Hill

Tindale R.S., Sheffey S. (2002), Shared information, cognitive load, and group memory, Group Processes and Intergroup Relations, Vol. 5 , No. 1, p. 5-18

Varvelli R., Varvelli M.L. (2001), How to make good decisions. Available at: http://www.varvelli.com/articoli

Vroom V.H., Yetton P.W. (1973), Leadership and decision making, Pittsburgh: University of Pittsburgh Press

Wallach M.A., Kogan N., Bem D.J. (1964), Diffusion of responsibility and level of risk taking in groups, Journal of Abnormal Social Psychology, Vol. 68, No. 3, p. 263-274

Wittenbaum G.M., Bowman J.M. (2004), A social validation explanation for mutual enhancement, Journal of Experimental Social Psychology, Vol. 40, No. 2, p. 169-184

Wittenbaum G.M., Hubbell A.P., Zuckerman C. (1999), Mutual enhancement: Toward an understanding of the collective preference for shared information, Journal of Personality and Social Psychology, Vol. 77, No. 5, p. 967-978

Wright B.E., Kim S. (2004), Participation's influence on job satisfaction, Review of Public Personnel Administration, Vol. 24, No. 1, p. 1840 